\title{
Tracking of fruit and vegetable consumption from childhood to adolescence: The Gateshead Millennium Study
}

\author{
J. K. Reilly ${ }^{1}$, L. Basterfield ${ }^{1}$, E. L. Slack ${ }^{1}$, K. N. Parkinson ${ }^{1}$, A. R. Jones ${ }^{1}$, M. S. Pearce ${ }^{2}$, A. Dale ${ }^{3}$, \\ A. S. Le Couteur ${ }^{2}$ and A. J. Adamson ${ }^{1}$ \\ ${ }^{1}$ Institute of Health \& Society, Human Nutrition Research Centre, Newcastle University, Newcastle upon Tyne NE2 4HH, \\ $U K,{ }^{2}$ Institute of Health \& Society, Newcastle University, Sir James Spence Institute, Royal Victoria Infirmary, Newcastle \\ upon Tyne NE1 4LP, UK and ${ }^{3}$ Queen Elizabeth Hospital, Gateshead NE9 6SX, UK
}

Current UK guidelines for fruit and vegetable consumption recommend both adults and children consume at least ' 5 -a-day'(1). Little is known to what extent fruit and vegetable consumption tracks from childhood to adolescence. The aim of this study was to assess fruit and vegetable consumption in Gateshead Millennium Study (GMS) participants at 6-8 years (baseline) and 11-13 years (follow-up) and determine the degree of tracking.

Longitudinal analysis of the GMS, a birth cohort recruited in 1999/2000 in northeast England ${ }^{(2)}$. Dietary intake was measured using age-appropriate assessment methods: at 6-8 years, the 'Food Assessment in Schools Tool' (FAST) assessed diet over 4 days (2 week days and 2 weekend days) ${ }^{(3)}$; at 11-13 years a self-completion 24-hour recall, $\left(\right.$ SCRAN24 $\left.{ }^{(4)}\right) \times 2$ days. Daily portions of fruit and vegetables consumed were calculated and adherence to UK 5-a-day recommendations assessed. Spearman's rank order correlation was performed to assess tracking from baseline to follow-up.

Data from 333 children (48\% male) were available from both baseline and follow-up. Fruit and vegetable consumption showed weak positive tracking $(r=0.23, p<0.001)$. Mean portions of fruit and vegetables consumed at baseline was significantly higher than at followup; 2.3 (sD1.22) compared with 1.7 (sD1.94) $(p<0.001$ ), although the number of children who met the 5-a-day target increased from $2.7 \%$ at baseline to $6.6 \%$ at follow-up. Only 2 participants achieved the 5-a-day target at both baseline and follow-up. The Table summarises portions of fruit and vegetables consumed by the cohort at baseline and follow-up in relation to UK 5-a-day guidelines.

\begin{tabular}{lccc}
\hline Total participants $=333$ & Met 5-a-day guidelines & Consumed $>0$ but 1 portions per day & Consumed 0 portions per day \\
\hline Baseline (6-8 years) & $9(2.7 \%)$ & $42(12.6 \%)$ & $5(1.5 \%)$ \\
Follow-up (11-13) years & $22(6.6 \%)$ & $144(43.2 \%)$ & $61(18.3 \%)$ \\
\hline
\end{tabular}

This study provides evidence of a degree of tracking of fruit and vegetable consumption from childhood to adolescence, and efforts to increase consumption in primary-age children and maintain this in adolescence should be increased.

This work was funded by Gateshead Primary Care Trust, University of Strathclyde and Breathe North.

1. NHS Choices (2013) Healthy Eating. http://www.nhs.uk/LiveWell/healthy-eating/Pages/Healthyeating.aspx (accessed 16/1/13 2013).

2. Parkinson KN, Pearce MS, Dale A et al. (2011) Cohort profile: the Gateshead Millennium Study. International journal of epidemiology 40, $308-317$.

3. Adamson AJ, Griffiths JM, Carlin LE et al. (2003) FAST: Food Assessment in Schools Tool. Proc Nutr Soc 62, 84A.

4. Foster E, Hawkins A, Delve J et al. (2013) Reducing the cost of dietary assessment: Self-Completed Recall and Analysis of Nutrition for use with children (SCRAN24). J Hum Nutr Diet In Press. 